\title{
ГЧП - фактор развития энергетики: международный опыт и практика России ${ }^{1}$
}

Л.А. толстолеСоВА, доктор экономических наук.

E-mail: I.a.tolstolesova@utmn.ru

М.C. ВОРОБЬЕВА, кандидат технических наук. E-mail: m.s.vorobieva@utmn.ru Н.H. ЮМАНОВА, кандидат экономических наук, Тюменский государственный университет, Тюмень. E-mail: n.n.yumanova@utmn.ru

Аннотация. В статье рассматриваются особенности использования механизма государственно-частного партнерства (ГЧП) в отечественном энергетическом секторе на современном этапе. Показано, что, в отличие от зарубежных стран, активно и эффективно реализующих энергетические ГЧП-проекты, в России и СНГ этот механизм пока не получил должного развития в секторе энергетики, хотя потребность в крупномасштабных инвестициях в отрасль очень велика. Анализ реализованных проектов ГЧП в энергетическом секторе РФ показал, что большинство из них имеют мелкий масштаб и относятся к муниципальному уровню. В основном это проекты, направленные на поддержание теплосетей и объектов энергоснабжения в рабочем состоянии. Они не смогут привести к значительным изменениям в отрасли и не способствуют созданию новых и модернизации действующих объектов энергоснабжения. Освещены проблемы, препятствующие развитию российской энергетики через институт ГЧП. Ключевые слова: государственно-частное партнерство; устойчивое развитие; инфраструктурные проекты; инвестиции; энергоснабжение и теплоэнергетика; муниципально-частное партнерство; направления и источники финансирования энергетики

\section{Развитие энергетики как условие устойчивого развития}

Концепция устойчивого развития отдельных стран и регионов прочно вошла в общественно-политический дискурс более двадцати лет назад, о чем свидетельствуют многочисленные международные конвенции, законодательные и программные документы разных стран. В качестве одного из важных ее элементов была выделена энергоэффективность. После многочисленных дискуссий о связи между энергетикой, окружающей средой и обществом ученые и политики согласились, что устойчивое

\footnotetext{
${ }^{1}$ Статья подготовлена при поддержке гранта РФФИ № 19-010-00975.
} 
развитие во многом зависит от эволюции применяемых энергетических технологий. В частности, в программных документах и многочисленных научных публикациях отмечается, что если в краткосрочном периоде неизбежна зависимость от ископаемых видов топлива, то в долгосрочной перспективе приоритетное развитие получат возобновляемые источники энергии, основанные на использовании энергии солнца, ветра, биомассы. Немаловажное значение будет иметь и ядерная энергия, при условии безопасной эксплуатации ядерных установок и обращения с радиоактивными отходами [National Research.., 1995].

При этом формирование структуры экономики, расширение и модернизация производств, развитие промышленной, транспортной, социально-бытовой инфраструктуры в значительной степени определяются существующим уровнем и возможностями наращивания энергомощностей.

Доступ к электроэнергии сегодня воспринимается как необходимое условие повышения качества жизни и борьбы с бедностью [Colombo, Mattarolo, 2017].

\section{Мировые тенденции реализации проектов ГЧП в сфере энергетики}

При реализации инфраструктурных проектов вообще и энергетических в частности, во многих странах мира все более популярным становится механизм государственно-частного партнерства (ГЧП), который можно рассматривать исходя из правовой и экономической природы.

По правовой природе он представляет собой систему установленных законов и нормативных актов, регулирующих проектный цикл, которая, возможно, потребует адаптации и некоторых изменений при переходе правительств к ГЧП [Public- Private.., 2014].

По экономической природе механизм государственно-частного партнерства отражает совокупность хозяйственных взаимоотношений на основе долгосрочного контракта между частной стороной и государственным органом на предоставление государственного актива или услуги, в рамках которого частная сторона несет значительный риск, а управленческая ответственность и вознаграждение связаны с выполнением работы [Public- Private.., 2014].

Из широкого спектра трактовок механизма государственно-частного партнерства, принятых в российской литературе, 
авторы для целей данного исследования использовали определение, предложенное коллегами из Финансового университета. Государственно-частное партнерство - это сотрудничество публичного и частного партнеров, основанное на объединении ресурсов и распределении рисков, которое осуществляется в целях привлечения в экономику частных инвестиций, повышения доступности и качества товаров, работ, услуг, обеспечение которыми потребителей обусловлено полномочиями органов государственной власти и органов местного самоуправления ${ }^{2}$ [Косов и др., 2019].

Проекты ГЧП, реализуемые в разных секторах экономики, особенно в сфере энергетики, активно поддерживаются и международными финансовыми институтами, поскольку создают условия для развития всей остальной инфраструктуры - производственной, инженерной, социальной.

Исследование развития ГЧП в энергетике в разных макрорегионах и странах мира, проведенное на основе отчета об участии частного сектора в инфраструктуре ГЧП и базы проектов ГЧП Всемирного банка, базы проектов Азиатского банка инфраструктурных инвестиций, Африканского банка развития, обзора инвестиционной деятельности международных банков развития, подготовленного Евразийским банком развития, показало степень их участия в финансировании и реализации проектов в энергетике, в том числе реализуемых на условиях ГЧП.

Одним из крупнейших международных инвесторов энергетических ГЧП-проектов является Всемирный банк в лице своих специализированных структур - Международного банка регионального развития (МБРР) и Международной ассоциации развития (МАР). Обе они поддерживают преимущественно крупные энергетические проекты в развивающихся регионах, особенно если они реализуются при государственном участии, в том числе на условиях ГЧП. За 2014-2018 гг. из общего объема их инвестиций в 218,3 млрд долл., вложения в развитие энергетики составили 32,6 млрд долл., или $15 \%{ }^{3}$.

${ }^{2}$ Косов М. Е., Сигарев А. В., Долина О.Н. и др. Государство и бизнес: основы взаимодействия: учебник. М.: ИНФРА-М, 2019. 295 с.

${ }^{3}$ Рассчитано на основе: Private Participation in Infrastructure (PPI). 2018. The Word Bank: IBRD-IDA: PPI Database, World Bank, as of April 2018: URL: http://ppi.worldbank. org/ /media/GIAWB/PPI/Documents/Global-Notes/H12018_PPI_Report (дата обращения: 26.06.2019). 
Азиатский банк инфраструктурных инвестиций за 20162018 гг. одобрил и профинансировал 43 проекта в разных странах, из них 14 (32,5\%) - в сфере энергетики. При общей стоимости проектов 15443,4 млн долл. участие банка составило 2658,5 млн $(17,2 \%)$. При этом было реализовано всего два проекта с государственным участием на сумму 125,9 млн долл. ${ }^{4}$

Африканским банком развития за 2016-2018 гг. было одобрено 46 проектов в сфере энергетики. При их общей стоимости 22310 млн долл. финансирование банка составило 11119 млн, или 49,8\%. Лишь в семи из этих проектов участвовали правительства соответствующих стран, вклад которых составил в общей сложности 1418 млн долл., или 6,7\% от стоимости всех проектов 5 .

Как видим из приведенных примеров, доля государств в реализации энергетических проектов, как правило, невысока. Это объясняется как небольшими бюджетными возможностями большинства развивающихся стран, так и высокими рисками таких проектов (риск при реализации будущей продукции, риск колебаний цен, риск развития альтернативных источников энергии, экологический риск и др.). Кроме того, не всегда законодательная база ГЧП и качество подготовки самих проектов соответствуют требованиям, которые предъявляют к ним международные финансовые институты, что неоднократно указывалось в отчетах этих организаций в качестве причин отказов в финансировании.

Несмотря на это, правительства стран инициируют разработку и реализацию проектов в сфере энергетики, поскольку они создают условия для развития других сфер инфраструктуры и секторов экономики.

Со своей стороны международные финансовые институты при отборе проектов для финансирования отдают предпочтение проектам с участием государства, как более надежным, поскольку их правовая основа более проработана, что позволяет распределить ответственность и снизить риски. Поэтому финансирование энергопроектов на условиях ГЧП распространяется все шире,

\footnotetext{
${ }^{4}$ Группировка проектов осуществлена на основе данных Азиатского банка инфраструктурных инвестиций: URL: https://www.aiib.org/en/projects/approved/index. html (дата обращения: 10.07.2019).

${ }^{5}$ Группировка проектов осуществлена на основе данных Африканского банка развития: URL: https://www.afdb.org/en/projects-and-operations (дата обращения: 01.07.2019).
} 
создавая основу для индустриального, аграрного и социального развития соответствующих стран.

Проведенное исследование реализации ГЧП-проектов в секторе энергетики, осуществляемых в разных макрорегионах и странах мира, позволило выделить несколько общемировых тенденций.

1. В развивающихся странах (Африка, Южная и Юго-Восточная Азия, Ближний Восток, Латинская Америка) наблюдается острая проблема обеспечения энергией и доступа к нейб ${ }^{6}$ В этих регионах энергетические объекты создаются, как правило, с нуля, с использованием новых технологий, нередко на основе возобновляемых источников энергии (ВИЭ). Строительство таких автономных энергоустановок осуществляется главным образом на удаленных и изолированных территориях, где высока доля дорогостоящего традиционного энергоснабжения. Такие проекты чаще всего сооружаются частными инвесторами. Они окупаются достаточно быстро за счет энергосервисных контрактов посредством значительной экономии топлива, которое частично замещается энергией солнца, ветра, воды. Так, Евразийский банк развития осуществляет поддержку проектов на основе ВИЭ исходя из принятых стратегий развития на 2013-2017 гг. и 2018-2022 гг. ${ }^{7}$ Всемирный банк осуществляет инвестиции в альтернативные энергетические проекты, отмечая, что они направлены на поддержку обеспечения занятости, развитие сельскохозяйственного производства и создание новых предприятий. Однако следует отметить, что речь идет, во-первых, о создании малых предприятий, а во-вторых, большинство этих проектов направлены на обеспечение коммунального энергоснабжения. K поставкам оборудования зачастую привлекаются фирмы-производители, являющиеся партнерами банков, или связанные лизинговые компании. Крупномасштабные энергетические проекты, если и поддерживаются международными финансовыми организациями, то обычно на основе софинансирования, где преобладают средства крупных частных компаний и банков, что

\footnotetext{
${ }^{6}$ Analysis of voluntary national reviews related to sustainable development.2018. Ensuring access to affordable, reliable, sustainable and modern energy for all. Published by the United Nations pp.7-8: URL: https://sustainabledevelopment.un.org/content/ documents/21159DESASDG7_VNR_Analysis2018_final.pdf (дата обращения: 28.06.2019).

${ }^{7}$ Стратегия Евразийского банка развития на период с 2018 по 2022год: URL https://eabr. org/upload/data/strategy_2018_2022. PDF (дата обращения: 17.07.2019).
} 
позволяет внедрять современные технологии и оборудование в сектор энергетики.

К примеру, структурами Всемирного банка за 2014-2018 гг. были профинансированы 47 ГЧП-проектов на основе ВИЭ на общую сумму 6975 млн долл. Это около 67\% всех поддержанных банком энергопроектов и 45,5\% соответствующих инвестиций ${ }^{8}$. В портфелях Азиатского банка инфраструктурных инвестиций и Африканского банка развития в сфере энергетики проекты на основе возобновляемых источников энергии составляют около $30 \%$.

Подчеркнем, что международная поддержка нередко предполагает не только непосредственное финансирование, но и техническое сопровождение проектов, вплоть до передачи его в эксплуатацию [Толстолесова, 2019].

2. Серьезной проблемой для многих стран является существующий разрыв в доступности электроэнергии между городскими и сельскими районами. Такие диспропорции охватывают почти $87 \%$ населения мира ${ }^{9}$, что сдерживает экономическое развитие сельских территорий. Одним из решений проблемы может стать строительство внесетевых источников на основе солнечной энергии (солнечные мини-сети, домашние солнечные системы). Примечательно, что в последние годы подобные проекты начали реализовываться не только в развитых (Канада, Австралия), но и в развивающихся странах Африки, Юго-Восточной Азии, в Палестине - для снабжения энергией коренных общин. Такие проекты часто финансируются путем объединения государственных и частных источников и нередко получают поддержку со стороны международных финансовых институтов.

3. В странах Европы энергетическая инфраструктура в основном создана давно, поэтому реализуемые здесь проекты государственно-частного партнерства чаще направлены на ее модернизацию, увеличение мощностей и/или переход на более экологичные и эффективные технологии и источники энергии. В 2014-2018 гг. общая стоимость вложений структур Всемирного

\footnotetext{
${ }^{8}$ Рассчитано на основе: Private Participation in Infrastructure (PPI). 2018. The Word Bank: IBRD-IDA: PPI Database, World Bank, as of April 2018: URL: http:// ppi.worldbank.org/ /media/ GIAWB/PPI/Documents/Global-Notes/H12018 PPI Report (дата обращения: 27.06.2019).

${ }^{9}$ Analysis of the voluntary national reviews relating to sustainable. Development goal 7: Ensuring access to affordable, reliable, sustainable 2018 and modern energy for all: United Nations, 2018-10p.P3: URL: https://sustainabledevelopment.un.org/content/ documents/21159DESASDG7_VNR_Analysis2018_final.pdf (дата обращения: 10.07.2019).
} 
банка в энергетические ГЧП-проекты европейских стран составила почти 5,5 млрд долл. (30\% всех инвестиций в энергетику) ${ }^{10}$.

Итак, в большинстве регионов мира механизм ГЧП не просто способствует более эффективному вовлечению частного бизнеса в крупные общественно-значимые проекты, реализуемые государством, но и позволяет внедрять новые технологии в сфере энергетики.

\section{Тенденции развития ГЧП в энергетике стран СНГ}

В странах СНГ, унаследовавших свое энергохозяйство от СССР, одной из главных проблем является значительная изношенность объектов энергетической инфраструктуры. Поэтому, несмотря на то, что механизм государственно-частного партнерства рассматривается ими «как один из главных инструментов привлечения бизнеса в развитие чистой энергетики» ${ }^{11}$, немногочисленные энергетические ГЧП-проекты, реализуемые в этих странах, направлены преимущественно на реконструкцию существующих объектов и повышение их эффективности.

Вообще же финансовое участие правительств СНГ в энергетических проектах пока весьма ограничено, в основном преобладают средства частных инвесторов и международных финансовых институтов.

Так, по состоянию на конец 2018 г. международные организации одобрили кредиты в секторе энергетики следующим странам (в млн долл.):

Азиатский банк развития: Таджикистан - 35; Туркменистан - 500; Узбекистан - 0,7. Европейский банк реконструкции и развития: Узбекистан-322,5; Казахстан-183; Украина - 85,9. Евразийский банк развития: Армения - 19,5; Казахстан 88; Россия - 295,212. Ни в одном из проектов, реализуемых с их поддержкой, государства не участвуют.

\footnotetext{
${ }^{10}$ Private Participation in Infrastructure (PPI). 2018. The Word Bank: IBRD-IDA: PPI Database, World Bank, as of April 2018: URL: http://ppi.worldbank.org/ /media/GIAWB/ PPI/Documents/Global-Notes/H12018_PPI_Report (дата обращения: 27.06.2019).

${ }^{11}$ Механизм государственно-частного партнерства в энергетике: страны Центральной Азии: Региональный экологический центр Центральной Азии: Алматы, 2018. 15 с. С. 2.

12 Рассчитано на основе: Обзор инвестиционной деятельности международных банков развития: IV кв. 2018 г. URL: https://eabr.org/upload/iblock/bda/Obzor-MBR-4kvartal-2018.pdf (дата обращения: 06.07.2019).
} 
В целом, анализ текущих портфелей ГЧП-проектов стран СНГ показывает, что энергопроекты занимают в них довольно скромное положение.

К примеру, в Республике Казахстан на сегодня заключено 74 договора ГЧП, 260 проектов находится на стадии рассмотрения, объявлено 60 конкурсов ${ }^{13}$. На долю проектов в области энергетики приходится всего $2 \%$ от общего числа, реализуемых на условиях ГЧП.

В Таджикистане на основе этого механизма реализовано несколько гидроэнергетических проектов, еще в 48 проектах строительства и реконструкции гидроэлектростанций ГЧП рассматривается в качестве возможного источника финансирования. В том числе правительство страны изучает возможность вхождения в проект восстановления генерирующих мощностей Нурекской ГЭС. Его стоимость составляет 350 млн долл., к финансированию привлечены Азиатский банк инфраструктурных инвестиций, Всемирный банк, Африканский банк развития, но все еще остается дефицит в 24 млн долл., который, возможно, будет покрыт из бюджетных средств, в результате чего проект приобретет статус ГЧП ${ }^{14}$.

В Кыргызстане механизм ГЧП начал развиваться лишь недавно, и делать какие-то выводы еще рано.

В Туркменистане механизм ГЧП в сфере энергетики пока не применяется, хотя правительство страны определило повышение энергоэффективности и внедрение возобновляемых источников энергии в качестве приоритетного направления развития страны.

В Узбекистане запущен процесс развития ГЧП, который рассматривает сектор энергетики в качестве отдельного направления. Инвестиционная программа страны включает 33 энергетических проекта на сумму 8,1 млрд долл. (в 2019 г. намечено реализовать семь из них на 620 млн долл.) ${ }^{15}$. Среди 15 ГЧП-проектов в разных сферах, предлагаемых иностранным инвесторам в 2019 г., к области энергетики относятся два -

\footnotetext{
${ }^{13}$ ГЧП Казахстан. URL: https://yvision.kz/post/774563 (дата обращения: 07.07.2019).

14 Данные Азиатского банка инфраструктурных инвестиций: URL: https:/www.aiib. org/en/projects/approved/index.html (дата обращения: 07.07.2019).

15 Проанализированы инвестиционные проекты в электроэнергетике. URL http://mineconomy.uz/ru/node/2493 (дата обращения: 19.07.2019).
} 
строительство солнечной электростанции в Самаркандской области и тепловой электростанции в Ташкенте - совокупной стоимостью 600 млн долл., ${ }^{16}$ или 36\% всех инвестиций в проекты ГЧП.

Правительство Азербайджана совместно с Азиатским банком развития в 2019 г. начало работу над созданием Центра развития государственно-частного партнерства. Крупными планируемыми проектами ГЧП являются два транспортных проекта (система легкорельсового транспорта в г. Баку и г. Сумгаит) общей стоимостью более 2 млрд долл. ${ }^{17}$ Проекты в сфере энергетики определены как приоритетные, но их разработка еще не начата.

В целом, приходится признать, что в странах СНГ механизм ГЧП не получил еще широкого распространения не только в секторе энергетики, но и других секторах экономики.

\section{Российская энергетика: особенности современного этапа развития}

В Российской Федерации ситуация в энергетическом секторе неоднозначна. Большинство эксплуатируемых энергообъектов созданы еще в советское время и требуют колоссальных вложений в реконструкцию и модернизацию основных фондов. На ближайшие десять лет потребность в финансовых ресурсах для модернизации энергетики оценивается в 3,5 трлн руб., в том числе: 1350 млрд руб. необходимо вложить в модернизацию 40ГВт тепловых мощностей; 950 млрд руб. - в объекты атомной энергетики; 405 млрд руб. - в реализацию проектов на основе возобновляемых источников энергии; 786 млрд руб. заложено на повышение цены конкурентного отбора мощности ${ }^{18}$.

В отчете министра энергетики А. Новака по итогам работы отрасли в 2017 г. отмечается, что за последние шесть лет «была реализована программа привлечения в отрасль инвестиций

\footnotetext{
${ }^{16}$ Узбекистан предлагает инвесторам проекты ГЧП на 1,66 млрд долл. URL: https://www.gazeta.uz/ru/2019/04/30/ investments/ (дата обращения: 19.07.2019).

${ }^{17}$ Сазонов B. E. Государственно-частное партнерство: гражданско-правовые, административно-правовые и финансово-правовые аспекты / кафедра административного и финансового права Российского университета дружбы народов / Предисл.д.ю.н., проф. А. Б. Зеленцова. М., 2012. 492 с.

${ }^{18}$ Итоги работы ТЭК России в 2017году: URL: https://www.ruscable.ru/news/2018/04/09/ itogi_raboty_TEK_Rossii_v_2017_godu/ (дата обращения: 07.07.2019).
} 
в объеме 2 трлн руб., что позволило на $15 \%$ обновить производственные мощности и сократить на $6 \%$ расходы топлива на отпуск электроэнергии» ${ }^{19}$.

Крупные энергетические компании, в основном с государственным участием (Концерн «Росэнергоатом», ПАО «РусГидро», группа «Интер РАО ЕЭС», Газпромэнергохолдинг, Госкорпорация «Ростех»), за счет собственных и заемных ресурсов, часто - при поддержке государства, не в рамках проектов ГЧП, реализуют масштабные проекты в области традиционной или альтернативной энергетики. Только в 2017 г. и 2018 г. были введены в эксплуатацию 18 энергоблоков суммарной мощностью более 4,8ГВт. Общий объем инвестиций составил 517 млрд руб., включая и бюджетные субсидии ${ }^{20}$. В 2018 г. объем введенных мощностей на основе ВИЭ составил 350 МВт, в 2019 г. потенциал его прироста может составить 1,5 ГВт, при условии полной реализации проектов ${ }^{21}$.

Неразвитость рыночных механизмов привлечения инвестиций привела к тому, что на сегодняшний день из пяти видов используемых инвестиционных механизмов лишь один основан на рыночных принципах 22 .

1. Относительно конкурентные рынки: РСВ (рынок «на сутки вперед»), КОМ (конкурентный отбор мощностей).

Неконкурентными или квазирыночными можно назвать:

2. Конкурсные договоры о предоставлении мощности (ДПМ), в том числе ДПМ возобновляемой энергетики.

3. Конкурсные ДПМ с локализацией по местоположению: КОМ нового генерирующего оборудования, ДПМ мусоросжигательных заводов.

\footnotetext{
${ }^{19}$ Итоги работы ТЭК России в 2017году: URL: https://www.ruscable.ru/news/2018/04/09/ itogi_raboty_TEK_Rossii_v_2017_godu/ (дата обращения: 07.07.2019).

${ }^{20}$ Итоги 2018: в 2018 году в России запущено 11 новых электростанций суммарной мощностью более 4 ГВт: https://sdelanounas.ru/blogs/116802/ (дата обращения: 09.07.2019).

21 Экспертное мнение ИПЕМ: Новые генерирующие мощности в ЕЭС России: анализ итогов 2018 года: Институт проблем естественных монополий, 2019.-6c.-C.2. URL: http://www.ipem.ru/files/files/research/20190201ipem_opinion_generation_2018.pdf (дата обращения: 20.07.2019).

22 Экспертное мнение ИПЕМ: Новые генерирующие мощности в ЕЭС России: анализ итогов 2018 года: Институт проблем естественных монополий, 2019.-6c.-C.4-5. URL: http://www.ipem.ru/files/files/research/20190201_ipem_opinion_generation_2018.pdf (дата обращения: 20.07.2019).
} 
4. Неконкурсные ДПМ и надбавки к цене оптового рынка: ДПМ ТЭС, договоры купли-продажи мощности ГЭС и АЭС, новые электростанции в Калининградской области и Крыму.

5. Бюджетное софинансирование: АЭС, новые ТЭС в Крыму и на Дальнем Востоке. Участие государства в финансировании таких проектов ограничено и осуществляется лишь в рамках целевых программ.

Крупные компании, как правило, реализуют масштабные проекты общегосударственного или межрегионального уровня, мелкие объекты местного значения не являются для них приоритетными по ряду причин.

Во-первых, мелкий масштаб проектов при одновременном значительном объеме работ и большом сроке окупаемости мало интересен крупным компаниям, а экономия, полученная от реализации таких проектов, может оказаться для них просто незаметной. Во-вторых, заемные источники, используемые традиционно в рамках проектного финансирования, вряд ли будут применимы из-за довольно высокой стоимости, а возможности региональных и местных бюджетов крайне ограничены. В-третьих, окупаемость муниципальных проектов в энергетике возможна при повышении тарифов для конечного потребителя, что сложно реализовать в условиях недостаточного платежеспособного спроса. Кроме того, налоговые льготы по региональным инвестиционным проектам имеют целый ряд ограничений и не способны существенно повлиять на налоговые платежи.

При этом износ основных фондов в энергохозяйствах регионального и муниципального уровней достигает порой 50-70\%, что ставит под угрозу надежность энергообеспечения целых населенных пунктов.

Отметим, что в ходе реформирования энергосистемы многие из распределительных сетей оказались в муниципальной (региональной) собственности, о плачевном состоянии бюджетов которых написаны горы литературы - большинству из них просто не по карману не то что модернизировать, но порой - даже содержать обветшавшее энергохозяйство. Одним из вариантов привлечения инвестиций в проекты по модернизации и реновации региональных и муниципальных энергообъектов является механизм государственно-частного партнерства. 


\section{Энергетические ГЧП-проекты регионального и муниципального уровня в России}

Механизм привлечения частных инвестиций в инфраструктурные проекты посредством ГЧП в России был запущен в 2005 г. с принятием закона «О концессионных соглашениях» (№ 115-Ф3). В 2016 г. вступил в силу также федеральный закон № 224-Ф3 от 13 июля 2015 г. «О государственно-частном партнёрстве, муниципально-частном партнёрстве в РФ...».

Информация о реализуемых в стране проектах ГЧП сосредоточена на сайте АНО «Национальный центр государственно-частного партнерства» - Платформа поддержки инфраструктурных проектов Росинфра (далее База проектов). База проектов формируется накопительным итогом с 2007 г. и находится в открытом доступе. В целях настоящего исследования мы проанализировали данные Базы по состоянию на 1 апреля 2019 г. На этот момент она включала 3939 проектов, в том числе 1625 - относящихся к сфере энергоснабжения ${ }^{23}$.

Проекты по энергоснабжению занимают самую весомую долю в общем количестве проектов (41\%), оставив далеко позади все прочие отрасли реализации государственно-частного партнерства. Однако общий объем привлеченного в них финансирования составляет всего $4 \%$ от совокупных инвестиций в проекты ГЧП. Это говорит о том, что в данном секторе реализуется большое количество мелких проектов (средний размер одного энергетического ГЧП-проекта составляет всего 142 млн руб., тогда как во всех остальных отраслях - 2208,5 млн руб.).

Львиную долю (88\%) от всех проектов ГЧП в энергетике занимают проекты по теплоснабжению. За 2007-2019 гг. на их реализацию привлечено 157,1 млрд руб. Однако средний объем инвестиций на 1 проект в электроснабжении в восемь раз выше, чем в теплоснабжении (табл. 1).

Реализация ГЧП в теплоснабжении обеспечивается в основном (95\%) механизмом концессии (табл. 2). Согласно концессионному соглашению одна сторона (концессионер) обязуется за свой счет создать (реконструировать, эксплуатировать) определенное

${ }^{23}$ Анализ проектов ГЧП в сфере энергетики проведен по данным официального сайта «Платформа поддержки инфраструктурных проектов» Национального центра государственно-частного партнерства. URL: http://www.pppi.ru/projects (дата обращения: 01.04.2019), расчеты авторов. 
имущество, принадлежащее другой стороне (концеденту) в обмен на право в течение определенного времени владеть и пользоваться этим имуществом, получая прибыль ${ }^{24}$. В общем и целом, смысл концессии состоит в том, чтобы путем вовлечения частного партнера в инфраструктурные проекты создать для него долгосрочную мотивацию по модернизации/управлению объектами концессии [Нефедкин и др., 2019].

\section{Таблица 1. Основные характеристики проектов ГЧП по энергетике В РФ по отраслям реализации (теплоснабжение, электроснабжение) по данным на 2019 г.}

\begin{tabular}{|l|c|c|}
\hline \multicolumn{1}{|c|}{ Показатель } & $\begin{array}{c}\text { Электро- } \\
\text { снабжение }\end{array}$ & $\begin{array}{c}\text { Теплоснаб- } \\
\text { жение }\end{array}$ \\
\hline $\begin{array}{l}\text { Количество проектов ГЧП в энергетике } \\
\text { по отраслям, ед. }\end{array}$ & 88 & 1537 \\
\hline Доля от общего количества проектов ГЧП в энергетике, \% & 5,4 & 94,6 \\
\hline $\begin{array}{l}\text { Объем инвестиций в реализацию проектов ГЧП по энергетике, } \\
\text { по отраслям, млн руб. }\end{array}$ & 73600,1 & 157100,9 \\
\hline $\begin{array}{l}\text { Доля от общего объема инвестиций в реализацию проектов ГЧП } \\
\text { по энергетике,\% }\end{array}$ & 31,9 & 68,1 \\
\hline $\begin{array}{l}\text { Объем инвестиций в реализацию проектов ГЧП по энергетике } \\
\text { на 1 проект, млн руб. }\end{array}$ & 836,4 & 102,2 \\
\hline
\end{tabular}

Источник: здесь и далее, если не указано иное, составлено авторами на основе данных http://www.pppi.ru/projects

\section{Таблица 2. Количество проектов ГЧП в теплоснабжении и объемы инвестиций по формам реализации проектов}

\begin{tabular}{|c|c|c|c|}
\hline \multirow{2}{*}{ Формы реализации проектов } & \multirow{2}{*}{$\begin{array}{c}\text { Количество } \\
\text { проектов, } \\
\text { ед. }\end{array}$} & \multicolumn{2}{|c|}{$\begin{array}{c}\text { Объем инвестиций } \\
\text { млн руб. }\end{array}$} \\
\hline & & общий & $\begin{array}{l}\text { на один } \\
\text { проект }\end{array}$ \\
\hline Договор аренды с инвестиционными обязательствами & 48 & 3173,7 & 66,1 \\
\hline Публичная инициатива (классическая конкурсная процедура) & 24 & 64,9 & 2,7 \\
\hline Концессионное соглашение (115-Ф3) & 1465 & 153862,3 & 105,0 \\
\hline
\end{tabular}

В электроэнергетике концессии довольно распространены (табл. 3), однако наиболее масштабные проекты реализуются в форме частной инициативы, предусматривающей упрощенный порядок или преференции для частного партнера - инициатора проекта.

\footnotetext{
${ }^{24}$ Федеральный закон от 21.07.2005 № 115-Ф3 «О концессионных соглашениях».
} 
Таблица 3. Количество проектов ГЧП в электроснабжении и объемы инвестиций по формам реализации проектов

\begin{tabular}{|c|c|c|c|}
\hline \multirow{2}{*}{ Формы реализации проектов } & \multirow{2}{*}{$\begin{array}{c}\text { Количество } \\
\text { проектов, } \\
\text { ед. }\end{array}$} & \multicolumn{2}{|c|}{$\begin{array}{l}\text { Объем инвести- } \\
\text { ций, млн руб. }\end{array}$} \\
\hline & & общий & $\begin{array}{l}\text { на один } \\
\text { проект }\end{array}$ \\
\hline Договор аренды с инвестиционными обязательствами & 11 & 19919,7 & 1810,9 \\
\hline $\begin{array}{l}\text { Частная инициатива (упрощенный порядок / преференции } \\
\text { для инициатора) }\end{array}$ & 5 & 31687,5 & 6337,5 \\
\hline Публичная инициатива (классическая конкурсная процедура) & 21 & 41,4 & 1,97 \\
\hline Концессионное соглашение (№115-Ф3) & 49 & 10941,3 & 223,3 \\
\hline Нет данных & 2 & 11010,2 & 5505,1 \\
\hline
\end{tabular}

Сравнительный анализ количества и объема инвестиций в проекты ГЧП по формам реализации указывает на более высокую заинтересованность участия частных инвесторов в проектах по электроснабжению. По нашему мнению, это обусловлено более высокой коммерческой привлекательностью таких проектов по сравнению с проектами теплоснабжения. Как отмечают эксперты, в России есть рынок электроэнергии, но нет рынка тепла. Кроме того, хронической проблемой теплоснабжения является неэффективное тарифное регулирование, что определяет состояние отрасли теплоэнергетики как устойчиво убыточное [Нефедкин и др., 2019].

Все энергетические ГЧП-проекты в исследуемый период реализуются на региональном либо муниципальном уровне. Подавляющая часть от общего количества проектов ГЧП по энергоснабжению реализуется на уровне муниципалитетов $(96,8 \%)$, их средняя стоимость невелика и составляет всего 102,9 млн руб. (табл. 4).

\section{Таблица 4. Основные характеристики проектов ГЧП по энергетике} в РФ по уровням реализации (федеральный, региональный, муниципальный) по данным на 2019 г.

\begin{tabular}{|l|c|c|}
\hline \multicolumn{1}{|c|}{ Показатель } & Муниципальный & Региональный \\
\hline $\begin{array}{l}\text { Количество проектов ГЧП в энергетике по уровню реали- } \\
\text { зации, ед. }\end{array}$ & 1573 & 52 \\
\hline Доля от общего количества проектов ГЧП в энергетике,\% & 96,8 & 3,2 \\
\hline $\begin{array}{l}\text { Объем инвестиций в проекты ГЧП по энергетике, по уровням } \\
\text { реализации, млн руб. }\end{array}$ & 161801,5 & 68899,6 \\
\hline $\begin{array}{l}\text { Доля от общего объема инвестиций } \\
\text { в ГЧП проекты по энергетике,\% }\end{array}$ & 70,1 & 29,9 \\
\hline Объем инвестиций на 1 проект, млн руб. & 102,9 & 1325,0 \\
\hline
\end{tabular}


Проекты регионального уровня (их в нашей выборке - 52) в среднем привлекают в 13 раз больше инвестиций, чем типичные муниципальные. Крупнейший из них реализуется на Урале. Это строительство энергоблока ПГУ-420 МВт на Верхнетагильской ГРЭС (собственник - «Интер РАО ЕЭС», объем инвестиций 22,1 млрд руб., механизм ГЧП - упрощенный порядок/преференции для инициатора).

По нашему мнению, более мелкий масштаб муниципальных проектов ГЧП объясняется двумя основными причинами: во-первых, муниципальные образования не нуждаются в крупных объектах энергоснабжения (зачем небольшому поселку ТЭЦ - достаточно котельной); во-вторых, средств муниципальных бюджетов недостаточно для участия в более дорогостоящих проектах.

Важное значение для развития энергетического комплекса страны имеет территориальное размещение объектов энергетики. Однако в случае с ГЧП-проектами географию определяют не столько объективные потребности, сколько имеющиеся бюджетные возможности регионов и муниципалитетов. Так, наибольший объем привлеченных инвестиций в энергетические ГЧП-проекты отмечен в Центральном федеральном округе (50618,8 млн руб., что в 2,2 раза больше, чем в Сибирском [Крюков, 2018]). Совокупная доля Центрального и Северо-Западного федеральных округов составляет $36,5 \%$ от всех российских инвестиций в проекты ГЧП по энергетике (табл. 5).

Таблица 5. Объемы инвестиций в проекты ГЧП по энергетике в регионах РФ, по данным на 2019 г., млн руб.

\begin{tabular}{|l|c|c|c|}
\hline Федеральный округ & Энергетика в целом & Электроснабжение & Теплоснабжение \\
\hline Центральный & 50618,8 & 5952,9 & 44665,9 \\
\hline Северо-Западный & 33721 & 9513,3 & 24207,8 \\
\hline Южный & 31117,5 & 943,9 & 30173,6 \\
\hline Северо-Кавказский & 645,9 & 3,3 & 642,6 \\
\hline Приволжский & 28144,2 & 11535 & 16609,2 \\
\hline Уральский & 31786,7 & 22321,6 & 9465,1 \\
\hline Сибирский & 24012 & 10061 & 13951 \\
\hline Дальневосточный & 30654,9 & 13269,3 & 17385,7 \\
\hline РФ & 230701 & 73600,3 & 157100,9 \\
\hline
\end{tabular}

В целом, можно отметить достаточно сильный разброс показателя инвестиций в разных федеральных округах. Для более 
корректного сравнения инвестиций по проектам ГЧП в энергетику регионов, проведем сравнительную характеристику объемов инвестиций на один проект и на душу населения. По результатам анализа самые низкие значения инвестиционных показателей демонстрирует Северо-Кавказский ФО (табл. 6).

\section{Таблица 6. Объемы инвестиций в проекты ГЧП по энергетике в регионах РФ на один проект и на душу населения B 2019 r.}

\begin{tabular}{|c|c|c|c|c|c|c|}
\hline \multirow[b]{2}{*}{$\begin{array}{c}\text { Федеральный } \\
\text { округ }\end{array}$} & \multicolumn{2}{|c|}{ Энергетика в целом } & \multicolumn{2}{|c|}{ Электроснабжение } & \multicolumn{2}{|c|}{ Теплоснабжение } \\
\hline & $\begin{array}{c}\text { на один } \\
\text { проект, } \\
\text { млн руб. }\end{array}$ & $\begin{array}{c}\text { на душу } \\
\text { населения, } \\
\text { тыс. руб. }\end{array}$ & $\begin{array}{c}\text { на один } \\
\text { проект, } \\
\text { млн руб. }\end{array}$ & $\begin{array}{c}\text { на душу } \\
\text { населения, } \\
\text { тыс. руб. }\end{array}$ & $\begin{array}{c}\text { на один } \\
\text { проект, } \\
\text { млн руб. }\end{array}$ & $\begin{array}{c}\text { на душу } \\
\text { населения, } \\
\text { тыс. руб. }\end{array}$ \\
\hline Центральный & 178,9 & 1,28546 & 1984,3 & 0,15117 & 159,5 & 1,13428 \\
\hline Северо-Западный & 177,5 & 2,41345 & 1057,0 & 0,68088 & 133,7 & 1,73258 \\
\hline Южный & 555,7 & 1,89111 & 943,9 & 0,05736 & 548,6 & 1,83375 \\
\hline Северо-Кавказский & 40,4 & 0,06546 & 3,3 & 0,00033 & 42,8 & 0,06513 \\
\hline Приволжский & 75,9 & 0,95738 & 501,5 & 0,39238 & 47,7 & 0,56499 \\
\hline Уральский & 274,0 & 2,57380 & 3720,3 & 1,80740 & 86,0 & 0,76640 \\
\hline Сибирский & 70,4 & 1,39822 & 346,9 & 0,58585 & 44,7 & 0,81237 \\
\hline Дальневосточный & 121,6 & 3,74361 & 829,3 & 1,62046 & 73,7 & 2,12316 \\
\hline РФ & 142,0 & 1,57174 & 836,4 & 0,50143 & 102,2 & 1,07031 \\
\hline
\end{tabular}

На наш взгляд, значительный региональный разброс показателей объема инвестиций на один проект (в энергоснабжении более чем в 1000 раз) и на душу населения (более чем в 5000 раз) требует дополнительного анализа и выявления объективных и субъективных факторов, определяющих существующую ситуацию. Проблемы неравномерного размещения проектов ГЧП на территории РФ и диспропорции в объеме привлекаемых по регионам инвестиций отмечают в своих работах и другие исследователи [Савруков и др., 2018].

Большая часть энергетических ГЧП-проектов имеет срок реализации от 11 до 20 лет (в базе по 90 проектам срок реализации не указан) (табл. 7). При этом прослеживается зависимость чем больше общий объем и объем инвестиций на 1 проект, тем длиннее сроки реализации проектов.

Актуальным вопросом развития ГЧП в России остается оценка эффективности реализации проектов, в том числе - с социально-экономической точки зрения. Приходится признать, что на официальном уровне соответствующие критерии, очевидно, 
мало принимаются во внимание. Во всяком случае, в базе проектов такая информация не отражается. Система оценки результатов в базе вообще отсутствует.

\section{Таблица 7. Количество проектов ГЧП по энергетике и объемы инвестиций по срокам реализации проектов}

\begin{tabular}{|l|c|c|c|}
\hline \multirow{2}{*}{ Срок реализации } & \multirow{2}{*}{ Количество проектов, ед. } & \multicolumn{2}{|c|}{ Объем инвестиций, млн руб. } \\
\cline { 3 - 4 } & & общий & на один проект \\
\hline До 5 лет & 428 & 9024,1 & 21,1 \\
\hline $6-10$ лет & 630 & 27132,9 & 43,1 \\
\hline $11-20$ лет & 337 & 68724,9 & 203,9 \\
\hline Более 20 лет & 140 & 85661,2 & 611,9 \\
\hline Нет данных & 90 & 40157,9 & 446,2 \\
\hline
\end{tabular}

Кроме того, в базе не раскрыто, как инвестиционный процесс по каждому из проектов развивается во времени, а некоторые эксперты с сожалением констатируют и отсутствие «релевантных текущих и перспективных оценок реального размера расходных обязательств по проектам, финансируемым за счет бюджета» [Савруков и др., 2018]. Точно также отсутствуют открытые данные о том, как выполняются обязательства, принятые сторонами партнерств.

Аналогичными дефектами страдает система критериев рейтинга российских регионов по уровню развития ГЧП. Основной показатель «Уровень развития ГЧП в субъектах РФ» содержит всего три компонента: развитие институциональной среды, наличие нормативно-правового обеспечения ГЧП и наличие опыта реализации проектов ГЧП в регионе ${ }^{25}$. То есть ни количественной, ни качественной оценки результатов взаимодействия бизнеса и государства рейтинг не предлагает.

\section{Заключение}

В развитых странах (и в развивающихся - при поддержке международных финансовых институтов) механизм ГЧП, как правило, выступает фактором инновационного развития энергетики. В развивающихся странах он также применяется в целях становления и развития энергетического сектора как такового.

\footnotetext{
${ }^{25}$ Рейтинг регионов. Официальный сайт «Платформа поддержки инфраструктурных проектов» Национального центра государственно-частного партнерства. URL: http://www.pppi.ru/regions (дата обращения: 01.04.2019).
} 
Однако в процессе отбора проектов ГЧП для финансирования международные институты сталкиваются с недостаточно высоким качеством разработки проектов и несовершенством законодательной базы, регулирующей данный механизм.

В Российской Федерации механизм ГЧП в большей степени используется для поддержания в работоспособном состоянии объектов энергетики, созданных в предшествующие периоды. Новое масштабное строительство энергообъектов, как правило, финансируется на основе других механизмов (ДПМ-1, RABрегулирование и т.д.).

Анализ проектов ГЧП, реализуемых в РФ на уровне регионов и муниципалитетов, позволил сделать следующие выводы:

- существуют серьезные различия в реализации энергетических ГЧП-проектов в разрезе отдельных регионов;

- в рамках ГЧП в энергетике реализуется значительное количество мелких по объему инвестиций проектов;

- основная часть проектов ГЧП в энергетике реализуется в теплоснабжении;

- подавляющая часть проектов ГЧП в энергетике осуществляется на муниципальном уровне, на региональном - преимущественно масштабные проекты по энергоснабжению;

- средний объем инвестиций в один проект ГЧП по электроснабжению значительно превышает средний объем инвестиций в проект по теплоснабжению;

• наблюдается значительный разброс значения показателя объема инвестиций в проекты ГЧП по энергетике в разных регионах РФ, что определяет диспропорции размещения региональных инвестиций в энергетику;

- актуальной проблемой развития института ГЧП в России остается отсутствие системы оценки эффективности партнерства.

В целом, пока трудно говорить о том, что проекты ГЧП в энергетике, реализуемые в РФ, выступают фактором развития. По большей части речь идет о поддержания энергохозяйства в рабочем состоянии.

\section{Литература/ References}

Крюков В.А. Изучение экономики Сибири: преемственность и комплексность // Регион: экономика и социология. 2018. № 2. С. 3-32. 
Kryukov, V.A. (2018). Study of Siberian economy: continuity and integrated approach. Region: Economics and Sociology. Region: ehkonomika i sotsiologiya. No. 2. Pp. 3-32. (In Russ.).

Нефедкин В.И., Фадеева О. П., Гинзбург Д. Р. Концессии в теплоснабжении: инвестиции вместо субсидий // ЭКО. 2019. № 3. С. 37-56.

Nefedkin, V.I., Fadeeva, O.P., Ginzburg, D.R. (2019). Consessions in heat supply: investments instead of subsidies. ECO. No. 3. Pp. 37-56. (In Russ.).

Савруков А.Н., Савруков Н.Т., Козловская Э.А. Оценка состояния и уровня развития проектов государственно-частного партнерства в субъектах РФ // Вопросы экономики. 2018. № 7. С. 131-141.

Savrukov, A.N., Savrukov, N.T., Kozlovskaya, Eh.A. (2018). Evaluating the state and development level in projects of State-private partnerships in subjects of the Russian Federation. Voprosy ehkonomiki. No. 7. Pp. 131-141. (In Russ.).

Толстолесова Л.А. Реализация инфраструктурных проектов государственно-частного партнерства в регионах мира при поддержке Всемирного банка: в сб. материалов XI Международной научно-практической конференции «Государство и бизнес: экосистема цифровой экономики», Санкт-Петербург, 24-26 апреля 2019 г./Северо-Западный институт РАНХиГС при Президенте РФ. Т. 2. 388 c.

Tolstolesova, L.A. (2019). Implementation of infrastructure projects via Stateprivate partnerships in various parts of the world with the World bank support: published as part of materials from the International scientific-practical conference 'The state and business': ecosystem of digital economy, St-Petersburg, April, 24-26 /Severo-Zapadnyj institut RANKHiGS pri Prezidente RF. T. 2. 388 p. (In Russ.).

Colombo, Emanuela, Mattarolo, Lorenzo. (2017). Energy and development: the role of academiain education, research, and technological cooperation for sustainability. WIREs Energy Environ., 6. Available at: https://doi.org/10.1002/ wene.215 (accessed 14.07.2019).

National Research Council. (1995). The Role of Technology in Environmentally Sustainable

Development. A Declaration of the Council of Academies of Engineering and Technological Sciences. CAETS. Kiruna, Sweden Washington, DC: The National Academies Press. Pp. 7-8. https://doi.org/10.17226/9236 (accessed 14.07.2019).

Public- Private Partnerships. Reference Guid: Version 2.0/ International Bank for Reconstruction and Development / The World Bank, Asian Development Bank, and Inter-American Development Bank. 2014. 232p. URL: http://documents.worldbank. org/ curated/en/600511468336720455/pdf/903840PPP0Refe0Box385311B000PUBL IC0.pdf (дата обращения: 16.07.2019).

Статья поступила 27.06.2019.

Для цитирования: Толстолесова Л.А., Воробьева М.С., Юманова Н.Н. ГЧП - фактор развития энергетики: международный опыт и практика России// ЭКО. 2019. № 9. С. 79-98. DOI: 10.30680/ECO0131-7652-2019-9-79-98. 


\section{Summary}

Tolstolesova, L.A., Doct. Sci. (Econ.), Vorobieva, M.S, Cand. Sci. (Tech.), Yumanova, N.N., Cand. Sci.(Econ.), Tyumen State University, Tyumen

PPP as a Factor in Development of Energy Sector: International Experience and Russian Practice.

Abstract. The article considers a possibility of using the mechanism of publicprivate partnership as a factor in development of energy sector. It is demonstrated that PPP projects in the field of energy, implemented in developing and developed countries with support of international financial institutions prove very efficiency and create conditions for development of industrial, engineering and social infrastructure. In the CIS countries and Russia, the PPP mechanism has not yet reached such development in the energy sector, although the need for large-scale investment in this industry is quite urgent. It is established that projects based on renewable energy sources are poorly implemented. The analysis of PPP projects in the energy sector of the Russian Federation and in the context of Federal districts reveals that Russia mostly implements small-scale projects at municipal level. And these are usually aimed at maintaining heating networks and power supply facilities in working condition. Such PPP projects can't lead to significant changes in the industry and do not contribute to creation of new and modernization of existing power supply facilities. The article reviews a number of obstacles that make development of the Russian energy sector through the PPP Institute rather problematic.

Keywords: Public-private partnership; sustainable development; infrastructure projects; investments; energy supply and heat power engineering; municipal-private partnership: directions and sources of energy financing

For citation: Tolstolesova, L.A., Vorobieva, M.S, Yumanova, N.N. (2019). PPP as a Factor in Development of Energy Sector: International Experience and Russian Practice. ECO. No. 9. Pp. 79-98. (In Russ.). DOI: 10.30680/ECO01317652-2019-9-79-98. 